\title{
Optical properties of the uropygial gland secretion: no evidence for $U V$ cosmetics in birds
}

\author{
Kaspar Delhey • Anne Peters • \\ Peter H. W. Biedermann • Bart Kempenaers
}

Received: 19 July 2007 / Revised: 8 May 2008 / Accepted: 14 May 2008 / Published online: 17 June 2008

(C) The Author(s) 2008

\begin{abstract}
Ultraviolet (UV) reflectance of the plumage is common in birds and plays an important role in sexual signalling. Recently, it has been proposed that birds are able to modify plumage UV reflectance by the application of uropygial gland secretion. Based on a survey of the optical properties of this secretion from 51 species belonging to 12 avian orders, we show that two main types of uropygial secretions exist, one predominantly found in passerines and one in non-passerines, both reducing relative UV reflectance of a white background (Teflon ${ }^{\mathrm{TM}}$ tape). We quantified how each type of secretion (exemplified by blue tit and mallard) affected feather UV reflectance. Both secretions reduced overall brightness and relative UV reflectance of white mallard feathers but hardly affected the reflectance of UV/blue blue tit crown feathers. According to models of avian colour vision, changes in reflectance due to application of the secretion were at or below the discrimination threshold of most birds. We conclude that the uropygial secretion is unlikely to play a major role in modifying
\end{abstract}

Electronic supplementary material The online version of this article (doi:10.1007/s00114-008-0406-8) contains supplementary material, which is available to authorized users.

K. Delhey $(\bowtie) \cdot$ A. Peters

Max Planck Institute for Ornithology,

Vogelwarte Radolfzell, Schlossallee 2,

78315 Radolfzell, Germany

e-mail: delhey@orn.mpg.de

P. H. W. Biedermann

Department of Behavioural Ecology, Institute of Zoology,

University of Bern,

Wohlenstrasse 50A, Hinterkappelen,

CH-3032 Bern, Switzerland

B. Kempenaers

Max Planck Institute for Ornithology,

Seewiesen, P.O. Box 1564, 82305 Starnberg, Germany plumage UV reflectance. However, the optical properties of the uropygial secretion may have been selected to interfere as little as possible with visual signaling through plumage reflectance.

Keywords Plumage colour · Preen gland - Avian vision . Sexual selection

\section{Introduction}

The recent recognition that birds are able to see in the nearultraviolet (UV) part of the spectrum $(\sim 300-400 \mathrm{~nm})$ has crucial implications for the interpretation of avian colours and transformed our understanding of avian sexual signalling (Bennett et al. 1997). Moreover, since some bird predators have poor UV sensitivity, the UV waveband has been considered a "private communication channel" for birds (Guilford and Harvey 1998; but see Hunt et al. 2001 and more recently Stevens and Cuthill 2007). Accordingly, UV reflecting plumage patches are found in most bird species (Eaton and Lanyon 2003) and UV reflectance is often associated with body parts used in sexual signalling (Hausmann et al. 2003). In the eastern bluebird (Sialia sialis) for example, higher UV reflectance may signal male competitive ability and more UV individuals are more successful at obtaining nestboxes (Siefferman and Hill 2005). Female choice may also select for exaggerated UV reflectance as shown in some blue tit (Cyanistes caeruleus) populations (Sheldon et al. 1999; Limbourg et al. 2004), and producing highly UV reflecting feathers may only be achieved by birds in top condition (Jacot and Kempenaers 2007). Finally, differences in UV reflectance have been hypothesised to aid in reproductive isolation between closely related species (Bleiweiss 2004), and UV reflec- 
tance in chicks and eggs may increase their detectability to parents (Aviles et al. 2006; Hunt et al. 2003).

UV reflectance in bird plumage is caused by physical interference of the incident light with tissue microstructure (Prum 2006). It is also affected by pigment deposition (Shawkey and Hill 2005; Prum 2006), and by substances such as dirt and fat (Örnborg et al. 2002; Zampiga et al. 2004). UV reflectance is particularly sensitive to such external influences (Örnborg et al. 2002) and it has been suggested that birds may modify UV reflectance of their plumage by applying uropygial gland secretion (Piersma et al. 1999). Thus, birds may be able to rapidly, and perhaps also reversibly, adjust UV reflectance of the plumage.

The secretion produced by the uropygial gland consists of a complex mixture of waxes, (Jacob and Ziswiler 1982) and is actively applied onto the feathers during preening. Sometimes the secretion is visibly coloured, and its application changes the colour of the plumage thus acting as a "cosmetic" (for example in the great hornbill, Buceros bicornis Vevers 1964; Kemp 2001). The function of cosmetic colour changes is unknown although it has been hypothesised that they may enhance sexual attractiveness or reduce conspicuousness to predators (see reviews in Montgomerie 2006b; Delhey et al. 2007). Generally, the secretion is colourless to our eyes, but if it affects UV reflectance (either increasing or decreasing it) it could act as an avian "UV-cosmetic" (Piersma et al. 1999). This possibility was recently tested in the red knot (Calidris canutus), where the chemical composition of the uropygial secretion changes dramatically from mono-ester to di-ester waxes prior to breeding (Reneerkens et al. 2002; Reneerkens et al. 2006). Despite differences in the optical properties of both types of secretion (di-ester waxes absorbed more UV light in vitro), their application did not change plumage reflectance (Reneerkens and Korsten 2004). However, given that the rusty red breeding plumage of the red knot reflects very little in the UV, the potential UV-absorbing effects of the secretion cannot be expressed. Therefore, even if a UV cosmetic function of the uropygial secretion is unlikely in this species, this might not be the case in other birds with UV-reflective plumage or if in other species the secretion increases, rather than decreases, UV reflectance. Thus, the aim of this study is to assess inter-specific variability in the optical properties of the uropygial secretion in the UV and visible spectrum and to experimentally test how its application affects UV-reflective plumage.

\section{Materials and methods}

We sampled uropygial gland secretion of 181 individuals, belonging to 51 species from 12 orders. We sampled on average four individuals per species (range, 1-20; see Table 1). Samples were obtained from wild or captive live birds during

Table 1 List of all species included in this study, including sample size, source of the birds, and average values representing the change in brightness and UV chroma ( $\Delta$ Brightness and $\Delta U V$ chroma) due to the uropygial secretion of each studied species

\begin{tabular}{|c|c|c|c|c|c|c|}
\hline Order & Species & $N$ & Source & Date & $\Delta$ Brightness & $\Delta \mathrm{UV}$-chroma \\
\hline Pelecaniformes & Phalacrocorax carbo & 5 & Radolfzell (frozen) & $?$ & -22.83 & -1 \\
\hline Ciconiiformes & Ciconia ciconia & 3 & Radolfzell (1 captive, 2 frozen) & Sep 2004 & -21.05 & -1.4 \\
\hline Anseriformes & Anas platyrhynchos & 6 & Seewiesen (captive) & Apr 2004 & -25.68 & -3.4 \\
\hline Falconiformes & Falco subbuteo & 1 & Radolfzell (frozen) & $?$ & -22.9 & -0.7 \\
\hline \multirow[t]{3}{*}{ Galliformes } & Tetrao urogallus & 3 & Radolfzell ( 2 captive, 1 frozen) & Sep 2004 & -26.84 & -1.4 \\
\hline & Coturnix coturnix & 3 & Radolfzell (captive) & Sep 2004 & -29.22 & -4.9 \\
\hline & Phasianus colchicus & 1 & Radolfzell (frozen) & $?$ & -11.96 & -0.1 \\
\hline Gruiformes & Gallinula chlorophus & 1 & Radolfzell (frozen) & $?$ & -17.88 & -0.4 \\
\hline \multirow[t]{6}{*}{ Charadriiformes } & Phalaropus lobatus & 2 & Barrow (wild) & Jun 2004 & -25.97 & -1.9 \\
\hline & Phalaropus fulicarius & 6 & Barrow (wild) & Jun 2004 & -23.14 & -3.1 \\
\hline & Calidris pusilla & 7 & Barrow (wild) & Jul 2004 & -23.98 & -1.2 \\
\hline & Calidris melanotos & 2 & Barrow (wild) & Jul 2004 & -30.34 & -1.6 \\
\hline & Calidris alpina & 1 & Barrow (wild) & Jun 2004 & -29.15 & -2.2 \\
\hline & Tryngites subruficollis & 1 & Barrow (wild) & Jun 2004 & -13.83 & -1.5 \\
\hline Psittaciformes & Agapornis sp. & 1 & Radolfzell (frozen) & $?$ & -20.62 & 0.5 \\
\hline Apodiformes & Apus melba & 3 & Biel, Switzerland (wild) & Jul 2004 & -9.51 & -0.7 \\
\hline Alcediniformes & Alcedo atthis & 2 & Radolfzell (wild) & Sep 2004 & -16.08 & -2.5 \\
\hline \multirow[t]{2}{*}{ Piciformes } & Dendrocopos major & 4 & Radolfzell (1 wild, 3 frozen) & Sep 2004 & -24.51 & 0.1 \\
\hline & Picus viridis & 1 & Radolfzell (frozen) & $?$ & -24.37 & -0.2 \\
\hline \multirow[t]{4}{*}{ Passeriformes } & Hirundo rustica & 1 & Radolfzell (wild) & Sep 2004 & -15.26 & 0.2 \\
\hline & Troglodytes troglodytes & 1 & Seewiesen (wild) & Aug 2004 & -16.91 & -0.3 \\
\hline & Prunella modularis & 3 & Seewiesen (wild) & Apr 2004 & -6.12 & 0.1 \\
\hline & Erithacus rubecula & 7 & Seewiesen and Radolfzell (wild) & Apr, Aug, & -17.5 & -0.5 \\
\hline
\end{tabular}


Table 1 (continued)

\begin{tabular}{|c|c|c|c|c|c|c|}
\hline \multirow[t]{2}{*}{ Order } & \multirow[t]{2}{*}{ Species } & \multirow[t]{2}{*}{$N$} & \multirow[t]{2}{*}{ Source } & \multirow[b]{2}{*}{ Sep 2004} & \multirow[t]{2}{*}{$\Delta$ Brightness } & \multirow[t]{2}{*}{$\Delta \mathrm{UV}$-chroma } \\
\hline & & & & & & \\
\hline & Phoenicurus ochrurus & 1 & Radolfzell (wild) & Sep 2004 & -14.28 & -0.6 \\
\hline & Phoenicurus phoenicurus & 1 & Radolfzell (wild) & Sep 2004 & -16.05 & -0.8 \\
\hline & Saxicola rubetra & 1 & Radolfzell (wild) & Sep 2004 & -29 & -0.8 \\
\hline & Turdus merula & 7 & $\begin{array}{l}\text { Seewiesen ( } 3 \text { wild) and Radolfzell } \\
\text { ( } 4 \text { frozen) }\end{array}$ & Aug, Sep 2004 & -22.71 & -1.4 \\
\hline & Turdus pilaris & 1 & Radolfzell (wild) & Aug, Sep 2004 & -19.39 & 0.9 \\
\hline & Turdus philomelos & 2 & Seewiesen and Radolfzell (wild) & Aug, Sep 2004 & -25.31 & -3.3 \\
\hline & Sylvia atricapilla & 7 & Seewiesen and Radolfzell (wild) & Aug, Sep 2004 & -17.11 & -0.9 \\
\hline & Sylvia borin & 2 & Radolfzell (wild) & Sep 2004 & -20.51 & 0.7 \\
\hline & Sylvia curruca & 1 & Radolfzell (wild) & Sep 2004 & -5.89 & 0.7 \\
\hline & Sylvia communis & 1 & Radolfzell (wild) & Sep 2004 & -7.59 & 0.4 \\
\hline & Acrocephalus scirpaceus & 4 & Radolfzell (wild) & Sep 2004 & -13.26 & -0.2 \\
\hline & $\begin{array}{l}\text { Acrocephalus } \\
\text { schoenbaenus }\end{array}$ & 2 & Radolfzell (wild) & Sep 2004 & -14 & -0.2 \\
\hline & Phylloscopus trochilus & 1 & Seewiesen (wild) & Aug 2004 & -14.59 & -1.6 \\
\hline & Phylloscopus collybita & 2 & Seewiesen and Radolfzell (wild) & Apr, Sep 2004 & -14.58 & -1 \\
\hline & Parus major & 20 & $\begin{array}{l}\text { Seewiesen }(17 \text { wild }) \text { and } \\
\text { Radolfzell } \\
(3 \text { frozen })\end{array}$ & Apr, Aug 2004 & -14.41 & -1.1 \\
\hline & Parus caeruleus & 15 & Seewiesen (wild) & Apr, Aug 2004 & -15.41 & -0.8 \\
\hline & Parus palustris & 4 & Seewiesen (wild) & Apr 2004 & -15.34 & -0.5 \\
\hline & Parus cyaneus & 1 & Radolfzell (frozen) & $?$ & -9.72 & 0.6 \\
\hline & Aegithalos caudatus & 4 & Seewiesen and Radolfzell (wild) & Apr, Sep 2004 & -10.98 & -0.3 \\
\hline & Sitta europaea & 10 & $\begin{array}{l}\text { Seewiesen (wild) and Radolfzell, } \\
\text { (6 wild, } 2 \text { frozen) }\end{array}$ & Aug, Sep 2004 & -21.58 & -1.6 \\
\hline & Corvus monedula & 8 & Starnberg (captive) & Aug 2004 & -27.63 & -1.7 \\
\hline & Sturnus vulgaris & 2 & Seewiesen (captive) & Apr 2004 & -18.02 & -1.1 \\
\hline & Sturnus roseus & 2 & Seewiesen (captive) & Apr 2004 & -15.72 & -0.6 \\
\hline & Fringilla coelebs & 2 & Seewiesen and Radolfzell (wild) & Aug, Sep 2004 & -25.93 & -2.2 \\
\hline & Carduelis chloris & 6 & Seewiesen and Radolfzell (wild) & Apr, Sep 2004 & -20.01 & -0.6 \\
\hline & Carduelis spinus & 4 & Seewiesen (wild) & Apr 2004 & -20.75 & -0.5 \\
\hline & Emberiza schoeniclus & 3 & Seewiesen and Radolfzell (wild) & Apr, Sep 2004 & -19.42 & -0.5 \\
\hline & Taeniopyga bichenovii & 2 & Starnberg (captive) & Apr 2004 & -17.85 & -1.3 \\
\hline
\end{tabular}

Radolfzell $\left(47^{\circ} 44^{\prime} \mathrm{N}, 8^{\circ} 58^{\prime} \mathrm{E}\right)$ and Seewiesen $\left(47^{\circ} 58^{\prime} \mathrm{N}, 11^{\circ} 14^{\prime} \mathrm{E}\right)$ are in southern Germany while Barrow $\left(71^{\circ} 17^{\prime} \mathrm{N}, 156^{\circ} 47^{\prime} \mathrm{W}\right)$ is in Alaska, USA. All birds were caught, or held in captivity under license from the respective countries. Frozen birds were stored at the Max Planck Institute for Ornithology in Radolfzell, and are represented mainly by birds found dead locally

spring and summer or from undated frozen specimens (Table 1). To assess whether freezing affected the optical properties of the secretion (effects on UV chroma and brightness, see below) we compared frozen and fresh secretions for the six species (Ciconia ciconia, Tetrao urogallus, Dendrocopos major, Turdus merula, Parus major and Sitta europaea) for which we had both frozen and fresh samples. Although frozen samples reduced UV chroma and brightness slightly more than fresh uropygial secretion (UV chroma, mean $_{\text {fresh }}=-1.1, \mathrm{SE}=0.32 ;$ mean $_{\text {frozen }}=-1.5, \mathrm{SE}=$ 0.46; Brightness, mean $_{\text {fresh }}=-21.4, \mathrm{SE}=2.3$; mean $_{\text {frozen }}=$ -23.9, $\mathrm{SE}=2.1$ ), this difference was not significant (Wilcoxon Matched-Pairs Signed Rank test, UV chroma, $Z=-0.94, p=$
0.35 ; brightness, $Z=-0.52, p=0.60)$. However, note that sample sizes are very small.

The uropygial gland opens to the exterior through a papilla which can be either feathered or naked, depending on the species (Jacob and Ziswiler 1982). From naked papillae, a small drop (1-2 $\mathrm{mm}$ in diameter) of secretion was gently expressed, picked up with a plastic spatula and smeared onto the measuring surface (see below). From feathered papillae, a few of the feathers, soaked in uropygial secretion, were collected and pressed on the measuring surface. In both cases the sampled secretion covered the measuring surface completely, and roughly similar amounts of secretion per unit of surface were applied in each case. 
The effect of applying uropygial secretion on reflectance was measured using a Avaspec 2048 spectrometer connected to a deuterium-halogen light source (Avalight-DHS, Avantes, Eerbek, Netherlands) through a bifurcated fibre optics cable fitted at the end with a plastic cylinder to standardise measuring distance and shield out ambient light. The probe was held perpendicular to the surface of the feathers hence illumination and recording angles were both $90^{\circ}$. Reflectance was computed relative to Teflon ${ }^{\mathrm{TM}}$ tape or relative to a WS-2 white standard using the program Avasoft 6.2.1.

First, we tested the effect of the uropygial substance on the reflectance spectrum of white Teflon ${ }^{\mathrm{TM}}$ tape. Applying the uropygial secretion resulted in a small (3-4 mm diameter) but visible 'greasy' spot on the tape. We let the spot air dry before taking five reflectance measurements between 300 and $700 \mathrm{~nm}$. The small size of the spot meant that the five reflectance readings were taken on the same spot (lifting the probe between measurements) and these five measurements were averaged to obtain one reflectance spectrum per individual. Reflectance spectra of the stains were computed relative to the reflectance of an adjacent spot of clean tape, which can be used as a white standard to calibrate reflectance measurements (Andersson and Prager 2006). From the average spectra we derived brightness, computed as the average reflectance between 300 and $700 \mathrm{~nm}\left(\mathrm{R}_{300-700}\right)$, and UV chroma, which is the percentage of reflectance in the near-UV range $\left(R_{300-400} /\right.$ $\mathrm{R}_{300-700} \times 100$; Andersson et al. 1998; Montgomerie 2006a). We computed the effect of the secretion on the reflectance of the Teflon ${ }^{\mathrm{TM}}$ tape as: change in brightness $=$ brightness ${ }_{\text {Teflon tape }}+$ secretion - brightness ${ }_{\text {Teflon tape }}$, change in UV chroma $=\mathrm{UV}$ chroma ${ }_{\text {Teflon tape }}+$ secretion $-\mathrm{UV}$ chroma ${ }_{\text {Teflon tape }}$. Per definition the average reflectance (brightness) and UV
Fig. 1 Inter-specific variability in the optical properties of uropygial gland secretion. Shown are the average effects of applying uropygial secretion of different species on the reflectance of white Teflon ${ }^{\mathrm{TM}}$ tape used as white standard. The dashed line at $100 \%$, represents the reflectance of the intact Teflon ${ }^{\mathrm{TM}}$ tape The six species (a-c non-passerines, $\mathbf{d}-\mathbf{f}$ passerines) were chosen to illustrate the range of variation. Vertical bars represent \pm 1 SD Average values (and SD's) are calculated using the average values for each individual (based on the five repeated measurements, see "Materials and methods"). Thus, sample size equals the number of individuals. For a complete overview of sampled species and reflectance spectra see Table 1 and $\mathrm{S} 1$
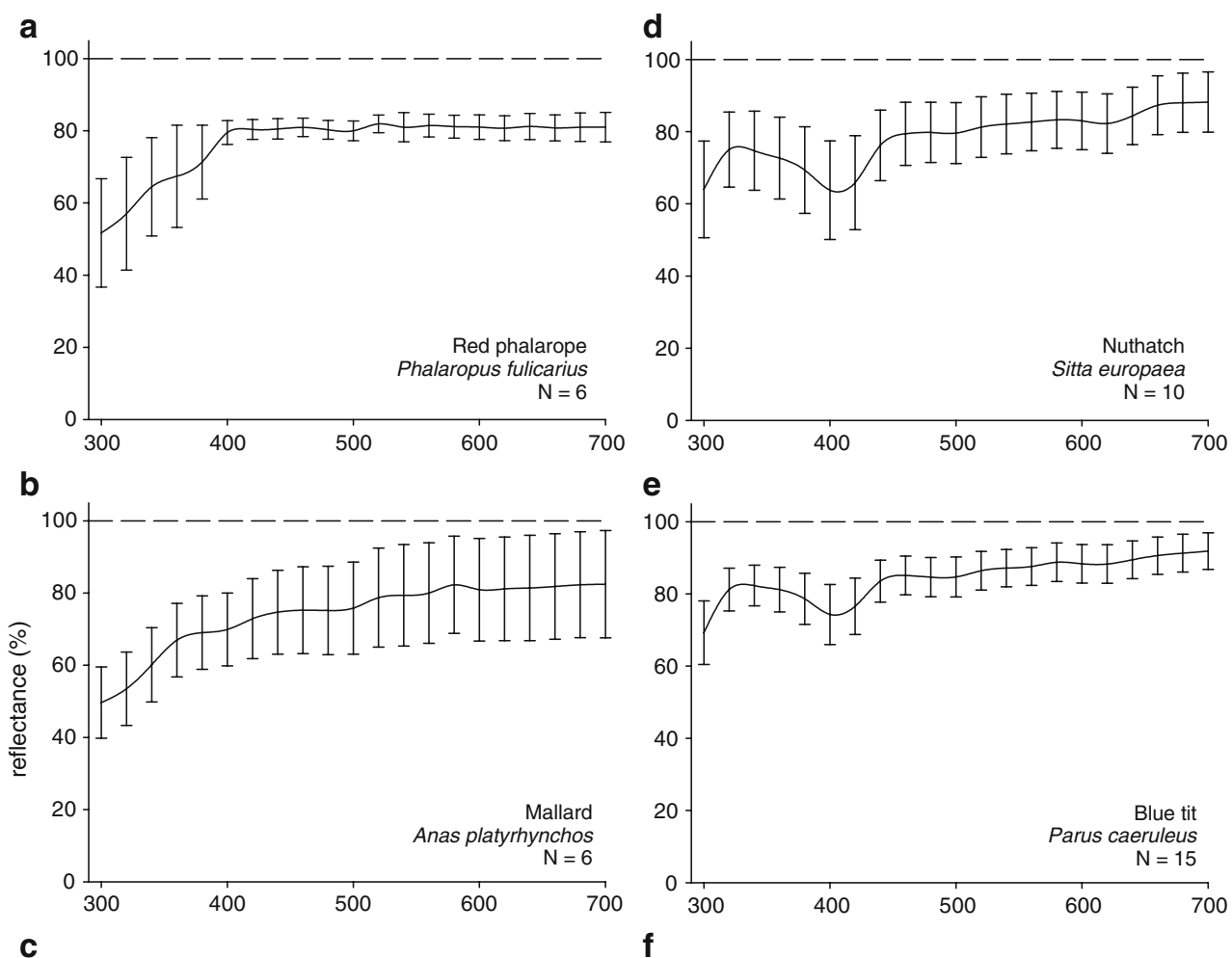

C

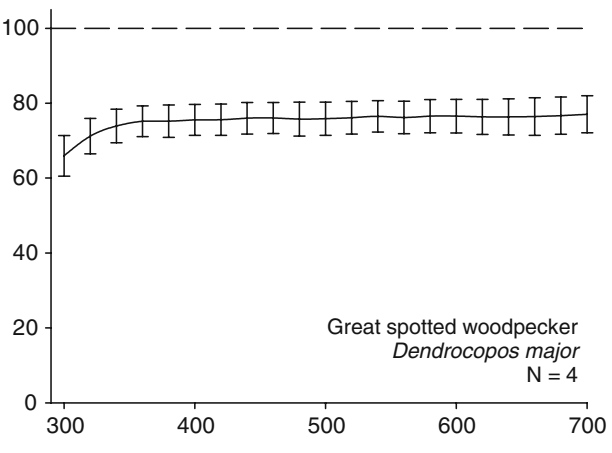

f

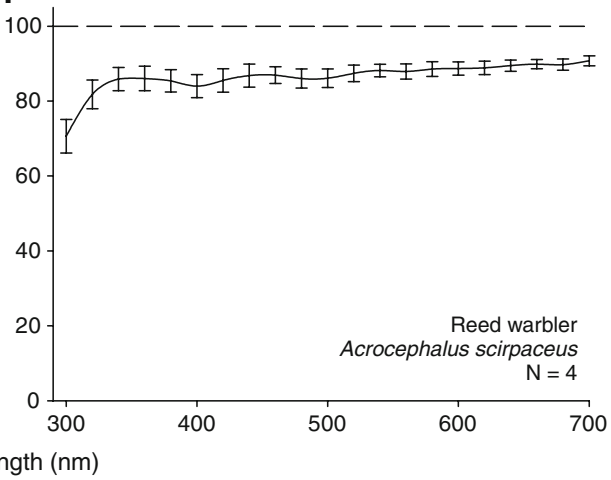


chroma of the white standard (clean Teflon ${ }^{\mathrm{TM}}$ tape) are $100 \%$ and $25 \%$ respectively.

Second, we assessed the effect of uropygial secretions on feather reflectance by comparing reflectance spectra before and after the application of the secretion. We sampled uropygial gland secretion and one feather type from one non-passerine (mallard, Anas platyrhynchos, the white tip of the feathers of the wing speculum, from five captive individuals) and one passerine (blue tit, $C$. (formerly Parus) caeruleus, UV/blue crown feathers, from four frozen specimens). This covered the two main types of secretion (see below). White feathers were chosen for their relatively uniform reflectance curve while blue tit crown feathers constitute a good example of a UV-rich sexually selected plumage patch (Andersson et al. 1998). We applied both types of secretion on different spots of both types of feathers. Reflectance of the same feather patch was measured five times before and five times after the application of uropygial secretion, using the same procedure as described above, but using a conventional white standard (WS-2, Avantes, Eerbek, Netherlands). We also quantified whether spectral differences would be visible to birds using a colour discrimination model (Vorobyev and Osorio 1998; Vorobyev et al. 1998). We used cone capture functions and visual parameters of UV-sensitive and violet-sensitive birds (from Endler and Mielke (2005)) to compute the chromatic distance $(\Delta S)$ in avian visual space between the average reflectance spectra of the feather before and after the application of the uropygial secretion. The unit for $\Delta \mathrm{S}$ is the jnd (just noticeable difference) and values of $\Delta \mathrm{S}>1$ can
Fig. 2 Effects of uropygial gland secretion on feather reflectance. Depicted are the effects of mallard and blue tit secretion on white mallard feathers and on UV/blue crown feathers of blue tits. Thick lines represent intact feathers, thin lines represent feathers with secretion applied and dashed lines are the difference in reflectance between intact feathers and feathers with secretion. Vertical bars represent $\pm 1 \mathrm{SE}$
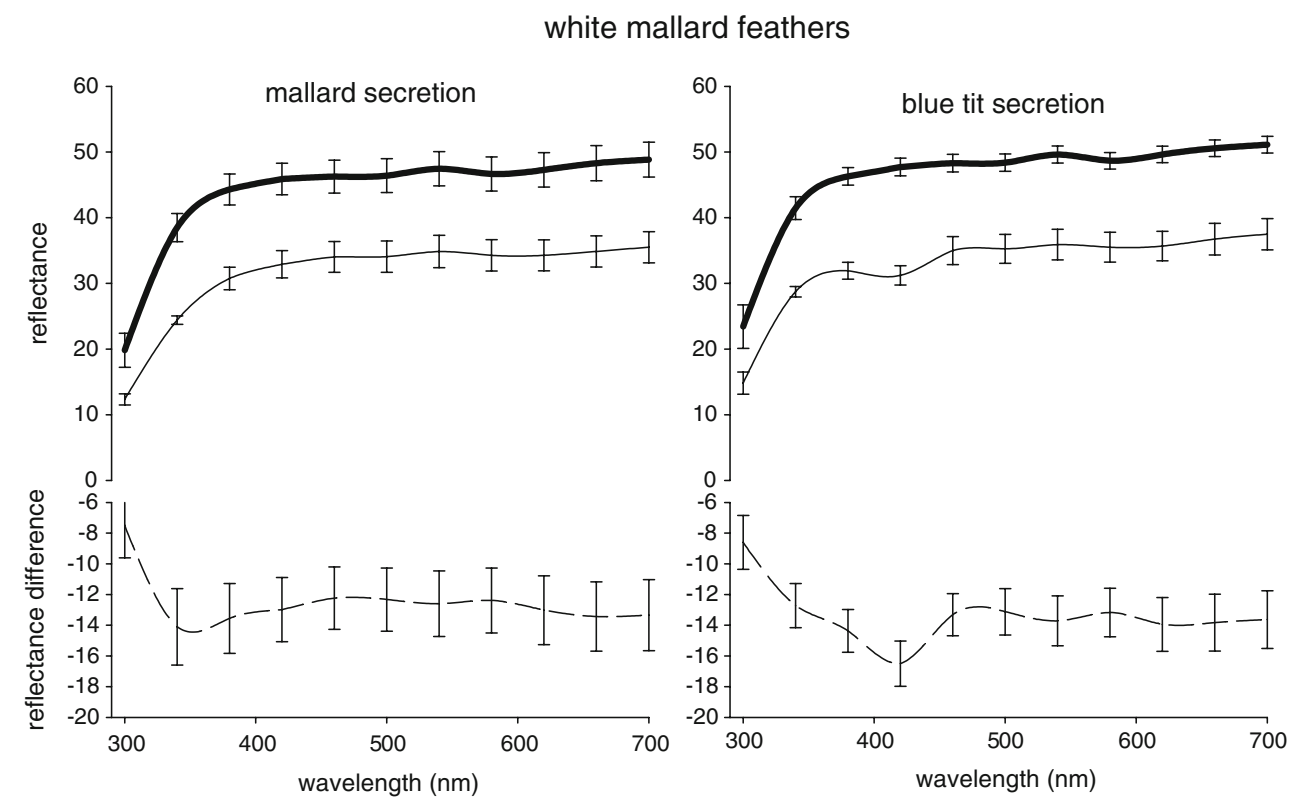

blue tit feathers
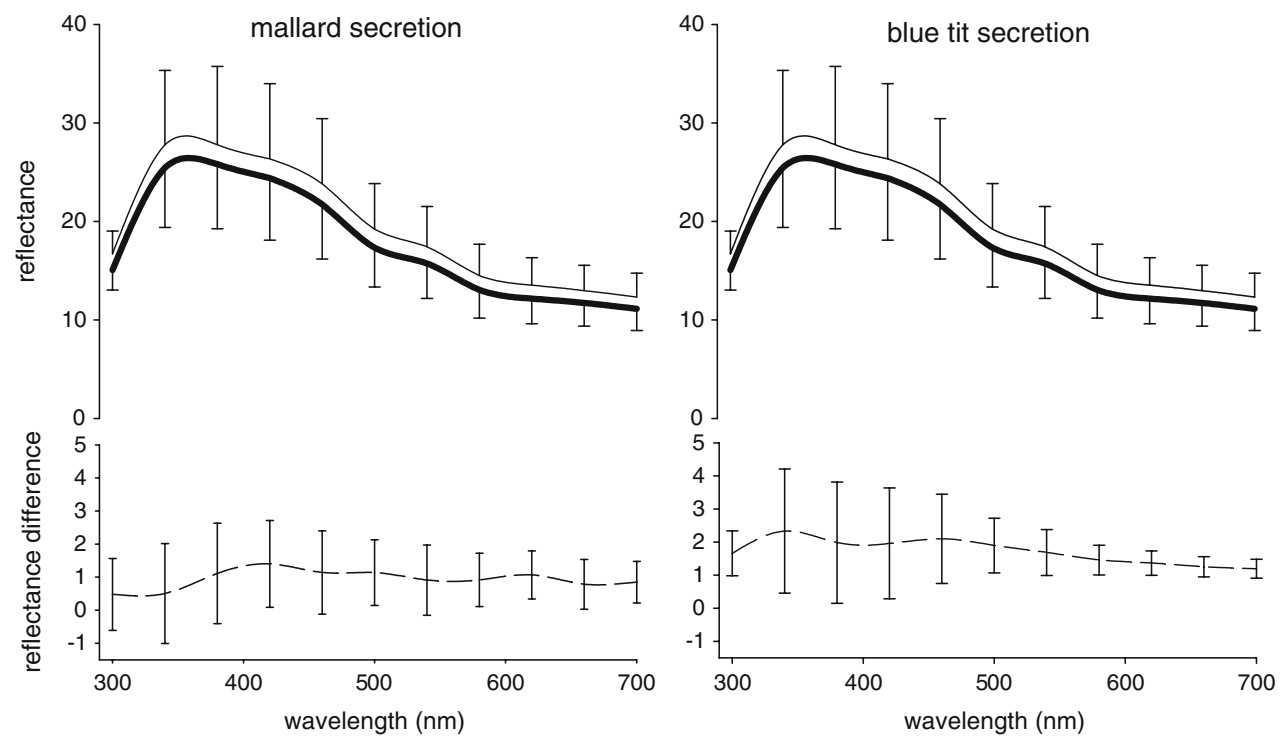
be discriminated by birds, whereas those below this threshold cannot. Note that $\Delta \mathrm{S}$ only refers to chromatic contrast, and disregards differences in brightness or luminance (achromatic contrast). For more details on visual modelling see the Appendix.

\section{Results}

In general the application of uropygial secretion had little effect on the reflectance at medium and longer wavelengths but considerably reduced reflectance of shorter wavelengths (Fig. 1, Table 1, S1). Although intermediates exist, we identified two main types of secretions based on how they affected reflectance at shorter wavelengths. Secretions that caused a decrease in reflectance in the UV (Fig. 1a-c), and secretions that, besides the decrease in reflectance in the UV range, also caused a discrete dip in reflectance at around 400-410 nm (Fig. 1d-f). This second type was only found among passerines.

Application of uropygial secretion reduced the brightness of the white surface (Fig. 1). This reduction was more marked among non-passerines $(-22 \%, \mathrm{SE}=1.34, n=19$ species) than among passerines $(-17 \%, \mathrm{SE}=0.99, n=32$ species; $\left.t_{49}=-3.09, p=0.003\right)$. Similarly, uropygial secretion reduced UV chroma of the Teflon ${ }^{\mathrm{TM}}$ tape more strongly in non-passerines $(-1.41, \mathrm{SE}=0.3)$ than in passerines $\left(-0.60, \mathrm{SE}=0.1 ; t_{27.4}=-2.37, p=0.027\right)$. The effect on UV chroma also seemed more variable among non-passerines than among passerines (95\% confidence interval, nonpasserines, -2.1 to -0.81 , passerines, -0.97 to -0.33 ; values from Table 1; also compare the reflectance spectra in S1 of the electronic supplementary material).

Application of the two main secretion types (mallard and blue tit) significantly reduced brightness of white mallard feathers, but not of blue tit feathers (Fig. 2; Table 2). UV chroma of the feathers was reduced by both types of secretion, but the effect was statistically significant only for mallard secretion applied on white mallard feathers (Table 2). Although some of the differences in UV chroma were statistically significant differences in spectral shape were rather subtle (Fig. 2). Analyses based on models of avian colour vision revealed that most of the differences in colouration caused by the secretion were below or at the detection limit (Table 2). As expected, $\Delta \mathrm{S}$ values were higher for highly UV-sensitive eyes (U-type eyes as found in rheas, gulls, parrots and Passerida; Endler and Mielke (2005)). However, even in these species, only the effects of the secretion on white feathers would be detectable $(\Delta S>1$; Table 2). The more noticeable effect of applying the secretion on white mallard feathers is possibly due to the latter's higher absolute brightness. This implies that the magnitude of the effect depends on the type of secretion and feather. Note,
Table 2 Effects of mallard and blue tit uropygial gland secretion on white mallard and UV/blue blue tit feathers

\begin{tabular}{lcc}
\hline & \multicolumn{2}{l}{ Changes due to } \\
\cline { 2 - 3 } & Mallard secretion & Blue tit secretion \\
\hline Mallard feathers $(N=5)$ & & \\
Brightness & $-12.8(2.2)^{* * *}$ & $-13.6(3.4)^{* * *}$ \\
UV chroma & $-1.5(0.3)^{* *}$ & $-0.7(0.3)^{*}$ \\
$\Delta \mathrm{S}$ (UV-type eyes) & 1.09 & 1.17 \\
$\Delta \mathrm{S}$ (V-type eyes) & 0.44 & 1.09 \\
Blue tit feathers $(N=4)$ & & $1.7(0.9)$ \\
Brightness & $1.1(1.1)$ & $-0.5(0.4)$ \\
UV chroma & $-0.8(0.3)^{*}$ & 0.50 \\
$\Delta \mathrm{S}$ (UV-type eyes) & 0.41 & 0.45 \\
$\Delta \mathrm{S}$ (V-type eyes) & 0.31 &
\end{tabular}

Shown are mean changes $( \pm$ SE) in brightness and UV chroma after application of the secretion and the chromatic distance in avian visual space or discriminability $(\Delta S)$ between reflectance spectra before and after application (see text for details). $p$ values indicate significance after paired $t$-tests

$* p<0.1$

$* * p<0.05$

$* * * p<0.01$

however, that our sample sizes are small, reducing the power to detect small differences in reflectance.

\section{Discussion}

Our survey of the optical properties of the uropygial gland secretion from 51 species suggests that the variability in uropygial secretion reflectance is largely restricted to UV and violet wavelengths (300-420 nm, Fig. 1). Interestingly, based on their optical properties, there seem to exist two types of secretion among the sampled birds. Secretion from non-passerine birds was characterised on average by moderate (but variable between species) reduction of overall reflectance and in particular UV reflectance. Passerine secretion on the other hand, showed less extreme effects but was characterised in most species by a discrete dip in reflectance around 400-410 nm (Fig. 1). Similar dips in this wavelength range have been found in reflectance spectra of structurally coloured bird integuments (Prum and Torres 2003), the ocular medium of bird eyes (Hart 2002) and urine of Australian marsupials (Kellie et al. 2004), but what causes these dips remains unclear.

The previous results suggest that uropygial secretion can only reduce, and not increase, feather UV reflectance and that it could possibly act as a UV cosmetic as proposed by Piersma et al. (1999). However, the application of both main types of secretion on feathers of mallards and blue tits revealed only subtle effects on feather reflectance that were barely discriminable by birds (Table 2, Fig. 2). Moreover, 
given that the amount of applied secretion probably exceeds the amount that birds normally preen onto their feathers, the changes in reflectance due to uropygial secretion reported here may be larger than those observed in nature.

We conclude that, at least among the sampled species, it is unlikely that secretions from the uropygial gland act as a UV cosmetic. However, note that seasonal and possibly also sexual variation in the optical properties of the uropygial secretion (e.g. Reneerkens et al. 2007) have not been specifically explored here and may need more attention before completely dismissing the UV-cosmetics hypothesis. Meanwhile, the lack of UV-cosmetic effects may simply reflect the fact that the optical properties of the uropygial secretions have been selected to interfere as little as possible with visual signalling through plumage colours. In favour of this hypothesis, most of the passerines included in this study have presumably highly UV-sensitive U-type eyes (except for the Jackdaw, Corvus monedula; Ödeen and Hastad 2003), whereas most of the non-passerines have violet-sensitive V-type eyes (except for the Lovebird, Agapornis sp.; Ödeen and Hastad 2003). It is therefore tempting to speculate that there is a link between UV sensitivity and uropygial secretion type. If UV signalling is more prevalent among birds with highly UV-sensitive eyes (Mullen and Pohland 2008), selection may favour uropygial secretions with increased UV transparency, as seen among passerines. However, this hypothesis must await rigorous testing through further sampling and phylogenetically controlled comparative analyses.

Acknowledgments We thank A. von Bayern, P. Bize, A. Denk, S, Engel, G. Hoffmann, A. Jacot, W. Fiedler, R. Lanctot, D. Schmidl, A. Schmidt, C. Schmidt-Wellenburg, K-H. Siebenrock, M. Valcû and W. Forstmeier for their help with the collection of samples, and $\mathrm{M}$. Griggio and two anonymous reviewers for comments and suggestions that improved the manuscript. The experiments comply with the current laws of the countries in which they were performed.

Open Access This article is distributed under the terms of the Creative Commons Attribution Noncommercial License which permits any noncommercial use, distribution, and reproduction in any medium, provided the original author(s) and source are credited.

\section{Appendix: visual modelling methods}

Diurnal birds seem to use four types of cones for colour vision (sensitive to very short (VS), short (S), medium (M), and long (L) wavelengths, Hart 2001). To compute the chromatic distance or discriminability in the avian visual space $(\Delta S)$ for both $U$ - and V-type eyes we used the model developed by Vorobyev and Osorio (1998) with data on eye type from appendix A in Endler and Mielke (2005). The model assumes that colour discriminability depends only on receptor noise and that differences in intensity (i.e. brightness) are disregarded (Vorobyev et al. 1998). This model accurately predicted colour discrimination ability in birds, bees and humans (Vorobyev and Osorio 1998) and has been successfully used to estimate detectability of birds to predators (Hastad et al. 2005) and sexual dichromatism (Eaton 2005).

Discriminability between two spectra was computed using the equation:

$$
\begin{aligned}
\Delta S^{2}= & \left(\omega_{1} \omega_{2}\right)^{2}\left(\Delta f_{4}-\Delta f_{3}\right)^{2}+\left(\omega_{1} \omega_{3}\right)^{2}\left(\Delta f_{4}-\Delta f_{2}\right)^{2} \\
& +\left(\omega_{1} \omega_{4}\right)^{2}\left(\Delta f_{3}-\Delta f_{2}\right)^{2}+\left(\omega_{2} \omega_{3}\right)^{2}\left(\Delta f_{4}-\Delta f_{1}\right)^{2} \\
& +\left(\omega_{2} \omega_{4}\right)^{2}\left(\Delta f_{3}-\Delta f_{1}\right)^{2}+\left(\omega_{3} \omega_{4}\right)^{2} \\
& \left(\Delta f_{2}-\Delta f_{1}\right)^{2} /\left(\left(\omega_{1} \omega_{2} \omega_{3}\right)^{2}+\left(\omega_{1} \omega_{2} \omega_{4}\right)^{2}+\left(\omega_{1} \omega_{3} \omega_{4}\right)^{2}+\left(\omega_{2} \omega_{3} \omega_{4}\right)^{2}\right)
\end{aligned}
$$

(equation 8 in Vorobyev et al. (1998) where

$$
\left.\Delta f_{i}=\ln \left[\int_{\lambda} R_{i}(\lambda) S_{a}(\lambda) I(\lambda) d \lambda / \int_{\lambda} R_{i}(\lambda) S_{b}(\lambda) I(\lambda) d \lambda\right)\right]
$$

(see equations 1, 2, 3 in Vorobyev et al. (1998)

and $\lambda$ indicates wavelength, $R_{\mathrm{i}}(\lambda)$ the sensitivity of cone type i, $S_{\mathrm{a}}(\lambda)$ the reflectance spectrum of the feather, $S_{\mathrm{b}}(\lambda)$ the reflectance spectrum of the background and $I(\lambda)$ the spectrum of irradiant light. Integration is done over the visible spectrum which for most birds encompasses 300 to $700 \mathrm{~nm}$ (Hart 2001). If both spectra to be compared are viewed against the same background, $\Delta \mathrm{S}$ is not affected by background reflectance which was thus set to unity. As irradiance source we used the spectrum of standard daylight D65 (Vorobyev et al. 1998). $\omega_{\mathrm{i}}$ represents receptor noise which should be constant under good lighting conditions (Vorobyev et al. 1998). To compute $\omega_{i}$ we used a Weber fraction of 0.05 and cone proportions of 1:1:2:2 for U-type eyes and 1:2:2:4 for V-type eyes (VS, S, M, L; (Endler and Mielke 2005)).

\section{References}

Andersson S, Prager M (2006) Quantifying Colors. In: Hill GE, McGraw K (eds) Bird Coloration. Vol. 1. Mechanisms and Measurements. Harvard University Press, Cambridge, Massachusetts, pp 41-89

Andersson S, Örnborg J, Andersson M (1998) Ultraviolet sexual dimorphism and assortative mating in blue tits. Proc R Soc Lond B 265:445-450

Aviles JM, Soler JJ, Perez-Contreras T (2006) Dark nests and egg colour in birds: a possible functional role of ultraviolet reflectance in egg detectability. Proc R Soc Lond B 273:2821-2829

Bennett ATD, Cuthill IC, Partridge JC, Lunau K (1997) Ultraviolet plumage colors predict mate preferences in starlings. Proc Natl Acad Sci USA 94:8618-8621

Bleiweiss R (2004) Ultraviolet plumage reflectance distinguishes sibling bird species. Proc Natl Acad Sci USA 101:16561-16564

Delhey K, Peters A, Kempenaers B (2007) Cosmetic coloration in birds: occurrence, function, and evolution. Am Nat 169:S145-S158 
Eaton MD (2005) Human vision fails to distinguish widespread sexual dichromatism among sexually "monochromatic" birds. Proc Natl Acad Sci USA 102:10942-10946

Eaton MD, Lanyon SM (2003) The ubiquity of avian ultraviolet plumage reflectance. Proc R Soc Lond B 270:1721-1726

Endler JA, Mielke PW (2005) Comparing entire colour patterns as birds see them. Biol J Linn Soc 86:405-431

Guilford T, Harvey PH (1998) Ornithology - the Purple Patch. Nature 392:867

Hart NS (2001) The visual ecology of avian photoreceptors. Prog Retin Eye Res 20:675-703

Hart NS (2002) Vision in the peafowl (Aves: Pavo cristatus). J Exp Biol 205:3925-3935

Håstad O, Victorsson J, Ödeen A (2005) Differences in color vision make passerines less conspicuous in the eyes of their predators. Proc Natl Acad Sci USA 102:6391-6394

Hausmann F, Arnold KE, Marshall NJ, Owens IPF (2003) Ultraviolet signals in birds are special. Proc R Soc Lond B 270:61-67

Hunt S, Cuthill IC, Bennett ATD, Church SC, Partridge JC (2001) Is the ultraviolet waveband a special communication channel in avian mate choice? J Exp Biol 204:2499-2507

Hunt S, Kilner RM, Langmore NE, Bennett ATD (2003) Conspicuous, ultraviolet-rich mouth colours in begging chicks. Proc R Soc Lond B 270:S25-S28

Jacob J, Ziswiler V (1982) The uropygial gland. In: Farner DS, King JR, Parkes KC (eds) Avian Biology, vol VI. Academic, New York, pp 199-324

Jacot A, Kempenaers B (2007) Effects of nestling condition on UV plumage traits in blue tits: an experimental approach. Behav Ecol $18: 34-40$

Kellie A, Dain SJ, Banks PB (2004) Ultraviolet properties of Australian mammal urine. J Comp Physiol A 190:429-435

Kemp AC (2001) Family Bucerotidae (Hornbills). In: Del Hoyo J, Elliot A, Sargatal J (eds) Handbook of the Birds of the World, vol 6. Lynx Edicions, Barcelona, pp 436-508

Limbourg T, Mateman AC, Andersson S, Lessells CM (2004) Female blue tits adjust parental effort to manipulated male UV attractiveness. Proc R Soc Lond B 271:1903-1908

Montgomerie R (2006a) Analyzing colors. In: Hill GE, McGraw K (eds) Bird Coloration. Vol. 1. Mechanisms and Measurements. Harvard University Press, Massachusetts, pp 90-147

Montgomerie R (2006b) Cosmetic and adventitious colors. In: Hill GE, McGraw K (eds) Bird Coloration. Vol. 1. Mechanisms and Measurements. Harvard University Press, Cambridge, Massachusetts, pp 399-427

Mullen P, Pohland G (2008) Studies on UV reflection in feathers of some 1000 bird species: are UV peaks in feathers correlated with violet-sensitive and ultraviolets-sensitive cones? Ibis 150:59-68
Ödeen A, Hastad O (2003) Complex distribution of avian color vision systems revealed by sequencing the SWS1 opsin from total DNA. Mol Biol Evol 20:855-861

Örnborg J, Andersson S, Griffith SC, Sheldon BC (2002) Seasonal changes in a ultraviolet structural colour signal in blue tits, Parus caeruleus. Biol J Linn Soc 76:237-245

Piersma T, Dekker M, Damste JSS (1999) An avian equivalent of make-up? Ecol Lett 2:201-203

Prum RO (2006) Anatomy, physics, and evolution of structural colours. In: Hill GE, McGraw K (eds) Bird Coloration. Vol. 1. Mechanisms and Measurements. Harvard University Press, Cambridge, Massachusetts, pp 295-353

Prum RO, Torres R (2003) Structural colouration of avian skin: convergent evolution of coherently scattering dermal collagen arrays. J Exp Biol 206:2409-2429

Reneerkens J, Korsten P (2004) Plumage reflectance is not affected by preen wax composition in red knots Calidris canutus. J Avian Biol 35:405-409

Reneerkens J, Piersma T, Damste JSS (2002) Sandpipers (Scolopacidae) switch from monoester to diester preen waxes during courtship and incubation, but why? Proc R Soc Lond B 269:2135-2139

Reneerkens J, Piersma T, Sinninghe Damsté JS (2006) Discerning adaptive value of seasonal variation in preen waxes: comparative and experimental approaches. Acta Zool Sin 52:272-275

Reneerkens J, Almeida JB, Lank DB, Jukema J, Lanctot RB, Morrison RIG, Rijpstra WIC, Schamel D, Schekkerman H, Damste JSS, Tomkovich PS, Tracy DM, Tulp I, Piersma T (2007) Parental role division predicts avian preen wax cycles. Ibis 149:721-729

Shawkey MD, Hill GE (2005) Carotenoids need structural colours to shine. Biol Lett 1:121-124

Sheldon BC, Andersson S, Griffith SC, Örnborg J, Sendecka J (1999) Ultraviolet colour variation influences blue tit sex ratios. Nature 402:874-877

Siefferman L, Hill GE (2005) UV-blue structural coloration and competition for nestboxes in male eastern bluebirds. Anim Behav 69:67-72

Stevens M, Cuthill IC (2007) Hidden messages: are ultraviolet signals a special channel in avian communication? Bioscience 57:501-507

Vevers HG (1964) Adornment by colour in man and other animals. Symp Inst Biol 12:133-139

Vorobyev M, Osorio D (1998) Receptor noise as a determinant of colour thresholds. Proc R Soc Lond B 265:351-358

Vorobyev M, Osorio D, Bennett ATD, Marshall NJ, Cuthill IC (1998) Tetrachromacy, oil droplets and bird plumage colours. J Comp Physiol A 183:621-633

Zampiga E, Hoi H, Pilastro A (2004) Preening, plumage reflectance and female choice in budgerigars. Ethol Ecol Evol 16:339-349 